www.jmscr.igmpublication.org

Index Copernicus Value: 79.54

ISSN (e)-2347-176x ISSN (p) 2455-0450

crossrefDOI: https://dx.doi.org/10.18535/jmscr/v7i1.198

\title{
Effect of Oxytocin on blood Pressure variation during Normal Delivery in Different Socio-Economic Groups
}

\author{
Authors \\ Anju Kumari ${ }^{1}$, Anita Kumari ${ }^{2 *}$, Ashok Sharan $^{3}$, Kamla Sharma ${ }^{4}$, Seema Kumari ${ }^{5}$ \\ ${ }^{1}$ Lady Medical Officer, Indira Gandhi Institute of Medical Sciences, Patna \\ ${ }^{2}$ Tutor, Department of Physiology, Indira Gandhi Institute of Medical Sciences, Patna \\ ${ }^{3}$ Professor \& HOD Physiology IGIMS Medical College, Patna \\ ${ }^{4}$ Retd. Associate Professor, Department of Physiology, Nalanda Medical College, Patna \\ ${ }^{5}$ Assistant Professor, Department of Community Medicine, Narayan Medical College\& Hospital, \\ Jamuhar, Sasaram, Bihar \\ *Corresponding Author \\ Dr Anita Kumari
}

Tutor, Dept of Physiology Indira Gandhi Institute of Medical Sciences, Sheikhpura, Patna, India

Email: dranisingh@ rediffmail.com, Phone: 7004536074

\begin{abstract}
Objectives: Present study was carried out to determine the variation of Blood Pressure (BP) during normal delivery and effect of oxytocin on BP in different socioeconomic groups to help in establishing better perinatal care towards achieving the goal of healthy mother and baby.

Materials and Method: Hundred cases of normal delivery were included in our study. Blood pressure was recorded at the time of admission, at onset of labour, after full dilatation of cervix, after delivery of baby, after Oxytocin injection and during puerperium.

Results: Upper middle class - Baseline mean Systolic blood pressure (SBP) and diastolic blood pressure $(D B P)$ were $117 \pm 5.56$ and $77.92 \pm 5.63 \mathrm{mmHg}$ respectively. There was significant rise in $S B P$ and $D B P$ at onset of labour (122.76. $\pm 4.82 \& 82.20 \pm 4.8 \mathrm{mmHg}$ respectively, $p<0.05)$. SBP and DBP fall significantly after oxytocin injection $(114.40 \pm 6.47 \& 75.24 \pm 4.98 \mathrm{mmHg})$.

Lower class - Baseline mean Systolic blood pressure (SBP) and diastolic blood pressure (DBP) were $119.32 \pm 6.03$ and $78.84 \pm 5.35 \mathrm{mmHg}$ respectively. There was significant rise in SBP and DBP at onset of labour (123.84 $\pm 5.34 \& 82.94 \pm 5.02 \mathrm{mmHg}$ respectively, $p<0.05)$. SBP and DBP fall significantly after oxytocin injection $(116.68 \pm 6.29 \& 75.08 \pm 4.77 \mathrm{mmHg})$.

Conclusion: There is wide variation in BP during normal delivery and it rises significantly at onset of labour and falls significantly after Oxytocin injection. Close monitoring of Blood pressure during normal delivery may result in better perinatal outcome.

Keywords: Normal Delivery, Diastolic Blood Pressure, Oxytocin, Systolic Blood Pressure, Variation.
\end{abstract}

\section{Introduction}

Childbirth is a most pleasurable event to the mother at the same time it is also a life-threatening event to her. It has long been recognized that the blood pressure rises during labour. Labor is a unique physiological situation involving major 
hemodynamic changes which could considerably impact blood pressure. Walter Radcliffe (1944) was the first person who had the honour to point out this interesting phenomenon. In another older study on 50 cases of normal labor they recorded variation of the maternal blood pressure. ${ }^{1}$ However, there are only a few relatively old studies that report normal values of BP during the first stage of labor. ${ }^{2-4}$

Oxytocin is a nine amino acid peptide that is synthesized in hypothalamic neurons and transported down axons of the posterior pituitary for secretion into blood. It was first discovered in 1909 by Sir Henry H. Dale ${ }^{5}$, and later synthesized in 1954 by du Vigneaud ${ }^{6}$. Oxytocin given to a woman during or immediately after the birth of her baby (prophylactically) is effective in reducing excessive bleeding after vaginal birth. The third stage of labour is the period between the birth of the baby and the delivery of the placenta. Excessive blood loss during this period or immediately thereafter can be prevented by giving oxytocin, which is a drug that makes the womb contract to close the blood vessels in the placenta and helps it separate from the wall of the uterus. Its main route of administration is parenteral. World Health Organisation recommended Oxytocin as the drug of choice for the active management of the third stage of labour.

Larger dose of oxytocin injected rapidly is known to produce various adverse effects such as hypotension, nausea, vomiting, chest pain, headache, flushing, myocardial ischemia, ST-T segment changes, pulmonary edema, severe water intoxication, and convulsion. ${ }^{7}$ The magnitude of these effects is dose-related. ${ }^{8}$ However, these effects are not widely appreciated by clinicians as highlighted in the Confidential Enquiry into Maternal Deaths (CEMD) published in 2001. ${ }^{9}$ Patients receiving an infusion were more haemodynamically stable. ${ }^{8}$ So, the present study was done with an aim to determine the variation of BP during different stages of normal delivery and effect of Oxytocin on BP during normal delivery.

\section{Materials and Method}

This study was done after obtaining the clearance from the Institute's Ethics Committee and written informed consent from all subjects. A total of 100 women were included in our investigation. The subjects were both primigravidae and multigravidae, selected from different socioeconomic groups. All these subjects were admitted for the management of labour in the Hospital for Woman, Nalanda Medical College Hospital, Patna. Each subject was required to have the following:-

\section{Inclusion Criteria}

Mother with Spontaneous labour with normal presentation at term with live foetus, absence of history of systemic disease, normal antepartum course, Blood pressure and haematocrit in normal range were included.

\section{Exclusion criteria}

Subjects with hypertension, diabetes mellitus, and toxaemia of pregnancy or taking medication which interfere with blood pressure were excluded. These cases are further divided in two groups upper middle class and lower class each having 50 subjects.

The series included only cases where a normal delivery was followed by uneventful third stage of labour. All of them were having intravenous rehydration with $5 \%$ dextrose. The only drug that was given customarily in all cases was Oxytocin (10 IU I.M.) after delivery of baby. The deliveries are all spontaneous and blood loss during the course of the labour is minimal. The placenta from all the subjects separated spontaneously, and was delivered within minutes after delivery. Blood Pressure was recorded at the time of admission, at onset of labour, after full dilatation of cervix, after delivery of baby, after oxytocin injection, and during puerperium. All data were expressed as mean standard deviation (SD.). A statistical analysis was done using graph pad instat software. Statistical significance was accepted at $\mathrm{P}<0.05$. 


\section{Results}

Table 1 Subject characteristics

\begin{tabular}{|l|c|c|}
\hline & Upper Middle Class & Lower Class \\
\hline Age $(\mathrm{yrs})$ & $24.04 \pm 5.279$ & $23.22 \pm 6.12$ \\
\hline Gravida & $1.8 \pm 0.5997$ & $1.6 \pm 0.4993$ \\
\hline Gestational weeks & $39.18 \pm 0.8391$ & $38.20 \pm 0.8151$ \\
\hline Hemodynamic variables & & \\
Baseline SBP (mmHg) & $117.52 \pm 5.56$ & $119.32 \pm 6.03$ \\
Baseline DBP $(\mathrm{mmHg})$ & $77.92 \pm 5.63$ & $78.84 \pm 5.35$ \\
\hline Neonatal Weight $(\mathrm{Kg})$ & $2.34 \pm 0.523$ & $2.15 \pm 0.493$ \\
\hline
\end{tabular}

All values are expressed as Mean \pm SD

Table 2 Systolic Blood Pressure recordings of the Study Subjects, of upper middle class ( $\mathrm{n}=50$ )

\begin{tabular}{|l|c|c|c|c|c|c|c|}
\hline SBP & Range & Mean & S.D. & S.E. of Mean & t value & p value & Inference \\
\hline On Admission & $100-130$ & 117.52 & 5.56 & 0.787 & & & \\
\hline At the onset of labour & $110-130$ & 122.76 & 4.82 & 0.681 & 4.84 & $<0.001$ & HS \\
\hline After full dilatation of cervix & $114-130$ & 123.76 & 3.95 & 0.559 & 6.47 & $<0.001$ & HS \\
\hline After delivery of baby & $100-130$ & 119.00 & 6.05 & 0.856 & 1.27 & $>0.05$ & NS \\
\hline After Oxytocin & $96-126$ & 114.40 & 6.47 & 0.914 & 2.59 & $<0.001$ & HS \\
\hline Taken in puerperium & $110-130$ & 118.46 & 5.50 & 0.778 & 0.85 & $>0.05$ & NS \\
\hline
\end{tabular}

NB: HS - Significant at $0.1 \%$ or $1 \%$. S- Significant at $5 \%$ level. NS - Not Significant.

Table 3 Systolic Blood Pressure recordings of the Study Subjects, lower class $(\mathrm{n}=50)$

\begin{tabular}{|l|c|c|c|c|c|c|c|}
\hline SBP & Range & Mean & S.D. & S.E. of Mean & t value & p value & Inference \\
\hline On Admission & $110-130$ & 119.32 & 6.03 & 0.853 & & & \\
\hline At the onset of labour & $110-134$ & 123.84 & 5.34 & 0.756 & 3.97 & $<0.001$ & HS \\
\hline After full dilatation of cervix & $114-134$ & 125.04 & 4.34 & 0.613 & 5.44 & $<0.001$ & HS \\
\hline After delivery of baby & $110-130$ & 120.40 & 4.81 & 0.681 & 0.99 & $>0.05$ & NS \\
\hline After Oxytocin & $100-130$ & 116.68 & 6.29 & 0.890 & 2.14 & $<0.05$ & S \\
\hline Taken in puerperium & $100-130$ & 118.60 & 6.68 & 0.945 & 0.57 & $>0.05$ & NS \\
\hline
\end{tabular}

NB: HS - Significant at $0.1 \%$ or $1 \% . S$ - Significant at $5 \%$ level. NS - Not Significant.

Table 4 Diastolic Blood Pressure recordings of the Study Subjects, of upper middle class $(n=50)$

\begin{tabular}{|l|c|c|c|c|c|c|c|}
\hline DBP & Range & Mean & S.D. & S.E. of Mean & t value & p value & Inference \\
\hline On Admission & $60-86$ & 77.92 & 5.63 & 0.796 & & & \\
\hline At the onset of labour & $70-90$ & 82.20 & 4.80 & 0.679 & 4.09 & $<0.001$ & $\mathrm{HS}$ \\
\hline After full dilatation of cervix & $70-90$ & 82.32 & 5.27 & 0.746 & 4.03 & $<0.001$ & $\mathrm{HS}$ \\
\hline After delivery of baby & $60-86$ & 79.16 & 5.32 & 0.752 & 1.13 & $>0.05$ & $\mathrm{NS}$ \\
\hline After Oxytocin & $58-84$ & 75.24 & 4.98 & 0.704 & 2.48 & $<0.05$ & $\mathrm{~S}$ \\
\hline Taken in puerperium & $64-84$ & 78.92 & 4.50 & 0.637 & 0.98 & $>0.05$ & $\mathrm{NS}$ \\
\hline
\end{tabular}

NB: HS - Significant at $0.1 \%$ or $1 \%$. S - Significant at $5 \%$ level. NS - Not Significant.

Table 5 Diastolic Blood Pressure recordings of the Study Subjects, of lower class $(n=50)$

\begin{tabular}{|l|c|c|c|c|c|c|c|}
\hline DBP & Range & Mean & S.D. & S.E. of Mean & t value & p value & Inference \\
\hline On Admission & $70-90$ & 78.84 & 5.35 & 0.756 & & & \\
\hline At the onset of labour & $70-90$ & 82.94 & 5.02 & 0.711 & 3.95 & $<0.001$ & HS \\
\hline After full dilatation of Cx & $72-90$ & 84.32 & 4.68 & 0.662 & 5.45 & $<0.001$ & HS \\
\hline After delivery o f baby & $70-90$ & 79.08 & 4.20 & 0.594 & 0.25 & $>0.05$ & NS \\
\hline After Oxytocin & $62-88$ & 75.08 & 4.77 & 0.674 & 3.71 & $<0.001$ & HS \\
\hline Taken in puerperium & $60-90$ & 77.12 & 6.22 & 0.880 & 1.48 & $>0.05$ & NS \\
\hline
\end{tabular}

NB: HS- Significant at $0.1 \%$ or $1 \%$. S - Significant at $5 \%$ level. NS - Not Significant.

Upper-middle class-Baseline mean Systolic blood pressure (SBP) and diastolic blood pressure (DBP) were $117 \pm 5.56$ and $77.92 \pm 5.63 \mathrm{mmHg}$ respectively. There was significant rise in SBP and DBP at onset of labour $(122.76 . \pm 4.82 \&$ $82.20 \pm 4.82 \mathrm{mmHg}$ respectively, $\mathrm{p}<0.05)$. SBP 
and DBP falls significantly after Oxytocin injection (114.40 $\pm 6.47 \& 75.26 \pm 3.19 \mathrm{mmHg})$.

Lower class- Baseline mean Systolic blood pressure (SBP) and diastolic blood pressure (DBP) were $119.32 \pm 6.03$ and $78.84 \pm 5.35$ $\mathrm{mmHg}$ respectively. There was significant rise in SBP and DBP at onset of labour (123.84 $\pm 5.34 \&$ $82.94 \pm 5.02 \mathrm{mmHg}$ respectively, $\mathrm{p}<0.05)$. SBP and DBP falls significantly after Oxytocin injection $(116.68 \pm 6.29 \& 75.08 \pm 4.77 \mathrm{mmHg})$.

\section{Discussion}

In the present series 100 cases of normal delivery has been observed which come at random from different socio economic groups. As we know delivery of child is physiological phenomenon in life of human being. Blood pressure changes either increase or decrease, both affects the baby and parturient, so we need to evaluate the variations in blood pressure changes. In our present study significant rise in systolic blood pressure and diastolic blood pressure has been seen at the time of onset of labour, after full dilatation of cervix and during uterine contractions. (Contractions increase the pressure upto $60 \mathrm{~mm}$ of $\mathrm{Hg}$ ). Significant fall in systolic blood pressure and diastolic blood pressure during normal labour has been seen mostly after Oxytocin injection. . When the blood pressure variations of upper middle class are compared with those of lower class of a comparable age, no significant difference is seen in this series of cases. It is therefore concluded that socioeconomic status has no influence on the blood pressure variations during Normal Delivery. Walter Radcliffe (1944) was the first person who had the honour to point out this interesting phenomenon. In another older study on 50 cases of normal labor they recorded variation of the maternal blood pressure. ${ }^{1}$ Edwards ${ }^{10}$ summarized that during labour both systolic and diastolic blood pressure rises, rise in blood pressure occur during uterine contractions and BP falls after delivery. During labour and delivery hemodynamic fluctuation can be profound. Each uterine contraction displaces 300 to $600 \mathrm{ml}$ of blood in to the general circulation. Stroke volume increases, with a resultant rise in cardiac output by an additional $50 \%$ with each contraction. Thus it is possible for the cardiac output during labor and delivery to be $75 \%$ above baseline. Mean arterial pressure also rise in part because of maternal pain and anxiety. Blood loss during delivery (300 to $400 \mathrm{ml}$ ) can contribute to hemodynamic stress. Hemodynamic changes during the postpartum state are equally dramatic. ${ }^{11}$ SBP and DBP values during labor are higher than those observed in the antepartum period. An SBP equal or higher than $150 \mathrm{mmHg}$ or DBP equal or higher than 91 $\mathrm{mmHg}$ are associated with an increased risk of early postpartum preeclampsia. ${ }^{12}$ Cardiac output is greatly influenced by the patient's position, especially during labor and delivery. Many women cannot tolerate the supine position, especially after 30 weeks gestation. Supine hypotension syndrome can decrease cardiac output by 30 to 40 percent. ${ }^{13}$ For safety, women are encouraged to maintain left uterine displacement either by elevation of the right hip or by positioning themselves on their sides. In this position, the uterus is not resting on the inferior vena cava, which may be compressed by an enlarged uterus decreasing blood flow back to the heart. With decreased blood flow to the heart, the heart rate often increases. As the placenta is delivered and the uterus contracts, there is an increased intravascular volume of approximately 500ml. ${ }^{14}$ During pregnancy, blood volume increases by 40 - 45 percent from non-pregnant levels. The increase is needed for extra blood flow to the uterus, the extra metabolic needs of fetus, and increased perfusion of others organs, especially the kidneys. Extra volume also compensates for maternal blood loss during delivery. ${ }^{15}$ In a series of 15 patients, they found a $9 \mathrm{mmHg}$ increase in mean arterial blood pressure (from 82 to $91 \mathrm{mmHg}$ ) when cervical dilatation reached $8 \mathrm{~cm}$. The authors attributed blood pressure increase to the effect of uterine contractions which cause an increase in both 
stroke volume and heart rate. ${ }^{4}$ The degree of blood loss depends on how quickly the placenta separates from the uterine wall and how well the uterine muscle contracts after delivery of the infant and the placenta. The best preventive strategy is active management of the third stage of labor. Active management, which involves administering a uterotonic drug with or soon after the delivery of the anterior shoulder, controlled cord traction, and, usually, early cord clamping and cutting, decreases the risk of postpartum haemorrhage (PPH) and shortens the third stage of labor with no significant increase in the risk of retained placenta. ${ }^{16} \mathrm{~A}$ bolus oxytocin injection of 10 IU was more effective than a dilute oxytocin infusion and not associated with adverse haemodynamic responses when used for PPHprophylaxis in women undergoing vaginal delivery. ${ }^{17}$ There is a review comparing prophylactic oxytocin with no uterotonics, within the context of both active and expectant management of third stage of labour, found that both intramuscular and intravenous routes were effective in terms of reducing PPH and the need for therapeutic uterotonics but lacked sufficient information about other important outcomes and adverse effects to assess their comparative efficacy and safety. ${ }^{18}$

\section{Conclusion}

There is wide variation in BP during normal delivery .Systolic and diastolic blood pressure rises at the time of onset of labour, after full dilatation of cervix and during uterine contractions. After Oxytocin injection, systolic blood pressure and diastolic blood pressure falls significantly. So, close monitoring of BP during normal delivery is needed for achieving better perinatal outcome.

Conflict of interest: None

Source of Funding: None

Ethical Clearance: None

\section{References}

1. Brown R.C. A study of the Maternal B.P. variations in 50 cases of normal labour with a consideration of the effects of analgesia, Anaesthesia,Vol.6:nos2 April 1951

2. Duvekot JJ, Cheriex EC, Pieters FA, Menheere PP, Peeters LH. Early pregnancy changes in hemodynamics and volume homeostasis are consecutive adjustments triggered by a primary fall in systemic vascular tone. Am J Obstet Gynecol 1993;169:1382-92.

3. Hendricks $\mathrm{CH}$, Quilligan EJ. Cardiac output during labor. Am J ObstetGynecol 1956;71:953-72.

4. Robson SC, Dunlop W, Boys RJ, Hunter S. Cardiac output during labour. Br Med J (Clin Res Ed) 1987;295:1169-72.

5. Dale HH. The action of extracts of the pituitary body .Biochemistry Journal 1909;4:427- 47.

6. Du Vigneaud V, Ressler C, Swan JM, Roberts CW, Katsoyannis PG, Gordon S. The synthesis of an octapeptide amide with the hormonal activity of oxytocin. Journal of the American Chemical Society 1954;75(19):4879-80:

7. Devikarani D, Harsoor SS. Are we using right dose of oxytocin? Indian $\mathrm{J}$ Anaesth 2010;54:371-3.

8. Weis FR Jr, Markello R, Mo B, Bochiechio P. Cardiovascular effects of oxytocin. Obstet Gynecol 1975;46:211-14

9. Why Mothers Die 1977-1999. The confidential enquiries into maternal deaths in the United Kingdom. London: RCOG Press, 2001

10. E. M.Edwards, The blood pressure in normal labour,June 1958; 65:367-370

11. Anjlimaroo, Prgnancy and Heart Disease, page no.816

12. J. Cohen et al. European Journal of Obstetrics \&Gynecology and Reproductive Biology 184 (2015) 103-107. 
13. Gandhi, M.M Malde, A., Kudalkar, A. \& Karnik, H. (2011). A Practical Approach to Anesthesia for Emergency Surgery. Jaypee Brothers Publishers, New Delhi, India.

14. Steer, P. et al (2006). Heart Disease and Pregnancy. The Royal College of Obstetricians and Gynaecologists. Henry Ling Ltd, Dorchester, UK. Section 5: Intrapartum Care. PP 285 - 294.

15. Sodre, P.M.(2010). Obstetrics \& Gynecology: Maternal Physiology Changes During Pregnancy. Retrieved June 2014 from: http://www.medstudents.com.br/ginob/gin ob5.htm

16. Anderson \& Etches (2007). Prevention and Management of Postpartum Hemorrhage. American Family Physician. Retrieved June 2014 from: http://www.aafp.org/afp/2007/0315/p875.h tml

17. Davies GA, Tessier JL, Woodman MC, Lipson A,Hahn PM. Maternal hemodynamics after oxytocin bolus compared with infusion in the third stage of labor: a randomized controlled trial.Obstetrics \&Gynecology2011;105 (2):294-9

18. Cotter AM, Ness A, Tolosa JE. Prophylactic oxytocin for the third stage of labour. Cochrane Database of Systematic Review 2001, Issue 4.[DOI:10.1002/14651858.CD001808] 